\title{
Tumor necrosis factor-related apoptosis-inducing ligand as a therapeutic option in urothelial cancer cells with acquired resistance against first-line chemotherapy
}

\author{
STEFAN VALLO ${ }^{1,2}$, HENNER STEGE ${ }^{1,3}$, MAXIMILIAN BERG ${ }^{1}$, MARTIN MICHAELIS ${ }^{4}$, \\ RIA WINKELMANN $^{5}$, FLORIAN ROTHWEILER ${ }^{1}$ and JINDRICH CINATL $\mathrm{Jr}^{1}$
}

\begin{abstract}
${ }^{1}$ Institute of Medical Virology, University Hospital Frankfurt, D-60596 Frankfurt am Main; ${ }^{2}$ Department of Urology, Hochtaunus-Kliniken, D-61352 Bad Homburg; ${ }^{3}$ Department of Dermatology, University Hospital Mainz, D-55101 Mainz, Germany; ${ }^{4}$ Centre for Molecular Processing and School of Biosciences, University of Kent, CT2 7NZ Canterbury, UK;

${ }^{5}$ Dr. Senckenberg Institute of Pathology, University Hospital Frankfurt, D-60596 Frankfurt am Main, Germany
\end{abstract}

Received August 24, 2019; Accepted December 9, 2019

DOI: 10.3892/or.2020.7487

\begin{abstract}
Patients with urothelial carcinoma frequently fail to respond to first-line chemotherapy using cisplatin and gemcitabine due to development of resistant tumor cells. The aim of the present study was to investigate whether an alternative treatment with tumor necrosis factor-related apoptosis-inducing ligand (TRAIL) that induces tumor cell death via the extrinsic apoptotic pathway may be effective against chemotherapy-resistant urothelial cancer cell lines. The viability of the urothelial cancer cell line RT112 and its chemotherapy-adapted sublines was investigated by MTT assay. The expression of anti-apoptotic proteins was determined by western blotting and the individual roles of cellular inhibitor of apoptosis protein (cIAP)1, cIAP2, x-linked inhibitor of apoptosis protein (XIAP) and induced myeloid leukemia cell differentiation protein (Mcl-1) were investigated by siRNA-mediated depletion. In particular, the bladder cancer sublines that were resistant to gemcitabine and cisplatin were cross-resistant to TRAIL. Resistant cells displayed upregulation of anti-apoptotic molecules compared with the parental cell line. Treatment with the second mitochondrial activator of caspases (SMAC) mimetic LCL-161 that antagonizes cIAP1, cIAP2 and XIAP resensitized chemoresistant cells to TRAIL. The resensitization of tumor cells to TRAIL was confirmed by depletion of antiapoptotic proteins with siRNA. Collectively, the findings of the present study demonstrated that SMAC mimetic LCL-161 increased the sensitivity of the parental cell
\end{abstract}

Correspondence to: Professor Jindrich Cinatl Jr, Institute of Medical Virology, University Hospital Frankfurt, 40 Paul-EhrlichStreet, D-60596 Frankfurt am Main, Germany

E-mail: cinatl@em.uni-frankfurt.de

Key words: bladder cancer, acquired drug resistance, TRAIL, SMAC mimetics, LCL-161, IAP, second-line therapy line RT112 and chemotherapy-resistant sublines to TRAIL, suggesting that inhibiting anti-apoptotic molecules renders TRAIL therapy highly effective for chemotherapy-sensitive and -resistant urothelial cancer cells.

\section{Introduction}

Patients with metastatic urothelial cancer of the bladder have limited therapeutic options. First-line cisplatin-based chemotherapy, usually consisting of gemcitabine and cisplatin, is only associated with a median survival of 12-14 month $(1,2)$. In addition, available second-line therapies with the vinca alkaloid vinflunine or immune checkpoint inhibitors, such as pembrolizumab (PD-1), nivolumab (PD-1), or atezolizumab (PD-L1) show only limited success in terms of prolongation of survival $(3,4)$. Therefore, improved novel therapies are urgently needed.

It has long been known that tumor necrosis factor (TNF) can induce selective death in tumor cells (5). Unfortunately, several studies have reported that TNF treatment induced a lethal inflammatory shock syndrome, which markedly limits its applicability as a selective cancer treatment (6). TNF $\alpha$-related apoptosis-inducing ligand (TRAIL) induces tumor cell death via the extrinsic apoptotic pathway without causing a lethal inflammatory shock syndrome (7-9). However, only a small proportion of patients in clinical trials responded to various drugs that targeted TRAIL death receptors $(10,11)$. In addition, several urothelial cancer cell lines appear to be resistant to TRAIL therapy (12). A possible reason for this resistance to TRAIL treatment is the presence of alterations in the apoptotic pathways (13). Restoring the integrity of apoptotic pathways in resistant cancer cells may be a promising new approach to overcoming TRAIL and chemotherapy resistance. Inhibitor of apoptosis proteins (IAP), including cellular inhibitor of apoptosis protein (cIAP)1, cIAP2 and X-linked inhibitor of apoptosis protein (XIAP), have been emerging as anticancer drug targets (14). The expression of IAPs contributes to drug resistance in bladder cancer (15). A possible strategy to resensitize tumor cells that are resistant to TRAIL therapy may be 
inhibition of IAPs with the second mitochondrial activator of caspases (SMAC) mimetic, LCL-161, which antagonizes cIAP1, cIAP2 and XIAP (16). SMAC mimetics are currently under preclinical and clinical development as anticancer drugs (17). LCL-161 is an orally bioavailable SMAC mimetic that was shown to be well-tolerated in phase I/II clinical trials, exhibiting no dose-limiting toxicity in the observed dosage range $(18,19)$.

The objective of the present study was to investigate the antitumoral activity of TRAIL and to explore a possible way of circumventing TRAIL resistance in a model of acquired chemotherapy resistance in urothelial carcinoma.

\section{Materials and methods}

Drugs. Cisplatin was purchased from Gry-Pharma and gemcitabine was obtained from Lilly Deutschland $\mathrm{GmbH}$. LCL-161 was purchased from Selleckchem. TRAIL (SuperKillerTRAIL ${ }^{\mathrm{TM}}$ ) was purchased from EnzoLifeSciences.

Cells. The RT112 cell line was obtained from the Leibniz-Institut DSMZ-Deutsche Sammlung von Mikroorganismen und Zellkulturen $\mathrm{GmbH}$. Mycoplasma testing was performed for the cell lines used. The cell lines have been authenticated by STR profiling. The drug-resistant sublines were established by continuous exposure to increasing drug concentrations, as described previously (20). Drug-resistant sublines were considered to be cross-resistant to another drug if the ratio $\mathrm{IC}_{50}$ drug-resistant subline/ $\mathrm{IC}_{50}$ respective parental cell line for this drug was $>2$. The drug-resistant sublines RT112 ${ }^{\mathrm{r}} \mathrm{CDDP}{ }^{1000}$ (cisplatin-resistant) and RT112 ${ }^{\mathrm{r}} \mathrm{GEMCI}^{20}$ (gemcitabine-resistant), were derived from the Resistant Cancer Cell Line collection (https://research.kent.ac.uk/ibc/the-resistant-cancercell-line-rccl-collection). All cell lines were grown in Iscove's modified Dulbecco's medium (IMDM) supplemented with $10 \%$ fetal calf serum (FCS; Gibco, Thermo Fisher Scientific Inc.), $100 \mathrm{IU} / \mathrm{ml}$ penicillin and $100 \mu \mathrm{g} / \mathrm{ml}$ streptomycin at $37^{\circ} \mathrm{C}$.

Viability assay. Cell viability was determined by the MTT dye reduction assay after $120 \mathrm{~h}$ of incubation modified as described previously (20). MTT assays were repeated 3 times. IC $_{50}$ values were defined as the drug concentration producing $50 \%$ growth inhibition relative to untreated controls. Calculations were performed with CalcuSyn software, version 1.1 (Biosoft).

RNA interference. Synthetic siRNA oligonucleotides targeting cIAP1, cIAP2 or XIAP (ON-TARGET plus SMART pool siRNAs) were purchased from Dharmacon via Thermo Fisher Scientific, Inc. The non-targeting siRNA ON-TARGET plus SMART pool (Dharmacon) was used as negative control. For transfection, cells were grown to $\sim 60-80 \%$ confluence, trypsinised, and $4 \times 10^{5}$ cells were resuspended in $2 \mathrm{ml}$ cell culture medium containing $50 \mathrm{nM}$ siRNA and $8 \mu$ l DharmaFECT 2 (Dharmacon). Experiments were repeated 3 times.

Western blotting. Cells were lysed in Triton X sample buffer and separated by SDS-PAGE. Proteins were detected using specific antibodies against $\beta$-actin (Sigma-Aldrich, Merck KGaA, cat. no. A2228, 1:5,000), TRAILR1 (DR4, EnzoLifeSciences, cat. no. ALX-804-912-0100, 1:5,000), TRAILR2 (DR5, EnzoLifeSciences, cat. no. ALX-210-743-C200, 1:1,000), TRAILR3 (DCR1, EnzoLifeSciences, cat. no. ALX-804-667-C100, 1:500), TRAILR4 (DCR2, EnzoLifeSciences, cat. no. ADI-AAP-371-E, 1:1,000), XIAP (Cell Signaling via New England Biolabs, cat. no. 14334, 1:1,000), cIAP1 (Cell Signaling via New England Biolabs, cat. no. 7065, 1:1,000), cIAP2 (Cell Signaling via New England Biolabs, cat. no. 3130, 1:1,000), and Mcl-1 (Cell Signaling via New England Biolabs, cat. no. 94296, 1:1,000) and were visualized by enhanced chemiluminescence using a commercially available kit (GE Healthcare). Experiments were repeated 3 times.

Statistical analysis. Statistical data analysis was performed with GraphPad Prism 5.0 (GraphPad Software, Inc.). Results are expressed as mean \pm standard deviation of at least three experiments. Comparisons between two groups were performed using Student's t-test. Comparisons among three or more groups were performed by ANOVA followed by the Student-Newman-Keuls test. P-values $<0.05$ were considered to indicate statistically significant differences.

\section{Results}

Effects of TRAIL monotherapy on urothelial cancer cell viability, baseline protein expression of TRAIL receptors and anti-apoptotic proteins in urothelial cancer cell lines, and effects of LCL-161 on tumor cell viability. The chemotherapy-naïve cell line RT112 was more sensitive to TRAIL treatment compared with its chemoresistant sublines $\left(\mathrm{IC}_{50}: 17.19 \pm 0.28 \mathrm{ng} / \mathrm{ml}\right.$ in RT112 vs. $42.79 \pm 2.82 \mathrm{ng} / \mathrm{ml}$ in $\mathrm{RT} 112^{\mathrm{r}} \mathrm{GEMCI}^{20}$ vs. $40.16 \pm 1.92 \mathrm{ng} / \mathrm{ml}$ in RT112 ${ }^{\mathrm{r}} \mathrm{CDDP}^{1000}$ ) (Table I).

The sensitivity of tumor cells may depend on the expression of TRAIL receptors and on the expression of anti-apoptotic proteins, including IAPs (cIAP1, cIAP2 and XIAP) and Bcl2 family members (Mcl-1) (11,21-24). Western blotting revealed upregulated expression of TRAILR1 in the chemoresistant sublines RT112 ${ }^{\mathrm{r}} \mathrm{GEMCI}^{20}$ and RT112 ${ }^{\mathrm{r}} \mathrm{CDDP}^{1000}$ compared with RT112 cells, but the expression of TRAILR2, TRAILR3 and TRAILR4 was not significantly different (Fig. 1). The expression of IAPs (cIAP1, cIAP2 and XIAP) was uniformly elevated in the chemoresistant sublines of RT112. Mcl-1 expression was also elevated in the resistant sublines of RT112 compared with that in parental cells (Fig. 1).

LCL-161 treatment was slightly more effective in chemotherapy-naïve RT112 cells compared with RT112 ${ }^{\mathrm{r}} \mathrm{CDDP}^{1000}$ cells $\left(\mathrm{IC}_{50}: 3.69 \pm 0.15 \mu \mathrm{mol} / \mathrm{ml}\right.$ in RT112 vs. $4.21 \pm 0.09 \mu \mathrm{mol} / \mathrm{ml}$ in $\left.\mathrm{RT}_{112}{ }^{\mathrm{r}} \mathrm{CDDP}^{1000}\right)$. Gemcitabine resistancedidnotaffect LCL-161 sensitivity $\left(\mathrm{IC}_{50}: 3.69 \pm 0.16 \mu \mathrm{mol} / \mathrm{ml}\right.$ in $\mathrm{RT} 112^{\mathrm{r}} \mathrm{GEMCI}^{20}$ ) (Table I).

The combination of TRAIL with LCL-161 achieved a significant enhancement of the antitumor effects in all tested cell lines (Table I).

Effects of TRAIL treatment on protein expression of TRAIL receptors and anti-apoptotic proteins in urothelial cancer cell lines. The expression of IAPs (cIAP1, cIAP2 and XIAP) was increased following incubation with TRAIL for $24 \mathrm{~h}$ in RT112 parental cells and drug-resistant sublines. Mcl-1 
Table I. IC $_{50}$ values following treatment of urothelial cancer cells with TRAIL and LCL-161.

\begin{tabular}{lccc}
\hline Cell line & TRAIL $(\mathrm{ng} / \mathrm{ml})$ & LCL-161 $(\mu \mathrm{M})$ & $\mathrm{IC}_{50}$ TRAIL $(\mathrm{ng} / \mathrm{ml})+0.6 \mu \mathrm{M}$ LCL-161 \\
\hline RT112 & $17.19 \pm 0.28$ & $3.69 \pm 0.15$ & $0.79 \pm 0.01^{\mathrm{a}}$ \\
RT112 $^{\mathrm{r}}$ GEMCI $^{20}$ & $42.79 \pm 2.82$ & $3.69 \pm 0.16$ & $4.01 \pm 0.20^{\mathrm{a}}$ \\
RT112 $^{\mathrm{r}}$ CDDP $^{1000}$ & $40.16 \pm 1.92$ & $4.21 \pm 0.09$ & $3.03 \pm 0.23^{\mathrm{a}}$
\end{tabular}

aSignificant differences compared with TRAIL monotherapy. The $\mathrm{IC}_{50}$ values of each drug were determined by MTT assay after $120 \mathrm{~h}$ of incubation. The values represent means of three independent experiments performed in triplicate \pm standard error of the mean. TRAIL, tumor necrosis factor-related apoptosis-inducing ligand.

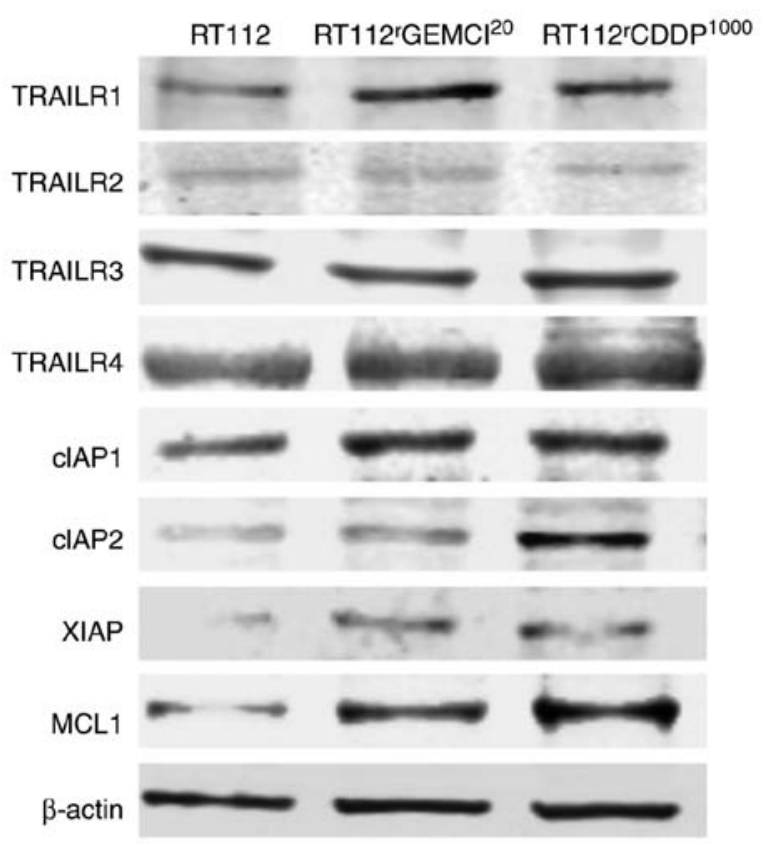

Figure 1. Evaluation of baseline protein expression. Western blotting showing protein expression of TRAIL receptors, IAPs and Mcl-1. The results shown are representative of three independent experiments. TRAIL, tumor necrosis factor-related apoptosis-inducing ligand; IAPs, inhibitors of apoptosis; cIAP, cellular inhibitor of apoptosis protein; XIAP, x-linked inhibitor of apoptosis protein; Mcl-1, myeloid leukemia cell differentiation protein 1; $\mathrm{RT} 12^{\mathrm{r}} \mathrm{GEMCI}^{20}$, gemcitabine-resistant RT112 subline; RT112 ${ }^{\mathrm{r}} \mathrm{CDDP}{ }^{1000}$, cisplatin-resistant RT112 subline.

expression did not increase following TRAIL treatment in chemotherapy-naïve and chemoresistant RT112 cells (Fig. 2).

Effects of combination therapy with TRAIL and LCL-161 on protein expression. LCL-161 treatment at a dosage far below the $\mathrm{IC}_{50}$ value (see Table I) did not change the protein expression of cIAP1, cIAP2, XIAP and Mcl-1 in RT112 parental cells and chemoresistant sublines. TRAIL treatment increased the expression of cIAP1, cIAP2 and XIAP in RT112 parental cells and chemoresistant sublines and the combination of LCL-161 with TRAIL again reduced the protein expression (Fig. 3).

Effects of RNAi-mediated depletion of cIAP1, cIAP2, XIAP and Mcl-1 on TRAIL sensitivity. cIAP1, cIAP2, XIAP and Mcl-1 were depleted using siRNA in RT112, RT112 ${ }^{\mathrm{r}} \mathrm{GEMCI}^{20}$ and $\mathrm{RT} 112^{\mathrm{r}} \mathrm{CDDP}^{1000}$ cells. Downregulation of cIAP1, XIAP and $\mathrm{Mcl}-1$ resulted in resensitization to TRAIL therapy. However, depletion of cIAP2 did not exert a significant effect on cell viability compared with TRAIL monotherapy (Fig. 4).

\section{Discussion}

The standard therapy for locally advanced or metastatic urothelial carcinoma of the bladder consists of the combination of gemcitabine and cisplatin $(1,2)$. Over the previous years, newly developed therapies, such as immune checkpoint inhibitors, were approved as second-line therapy following initial failure of cisplatin-based chemotherapy or for patients who are not eligible for cisplatin-based chemotherapy as a first-line therapy $(4,25)$. However, the success of the new therapeutic options has also been very limited and further antitumor therapies are needed $(4,25)$. The prognosis is mostly affected by development of acquired resistance.

TRAIL is known to induce tumor cell death without causing a lethal inflammatory shock syndrome, as was reported for TNF treatment (7-9). Using TRAIL as an antitumor therapy for bladder cancer had already been suggested $(24,26)$, but its role had not yet been investigated in an acquired chemotherapy resistance model. Cancer cell lines with acquired resistance to anticancer drugs were demonstrated to reflect the characteristics of clinical acquired drug resistance (27-29). In the present study, a well-established urothelial cancer cell model of acquired chemotherapy resistance was used to study the role of TRAIL as a pro-apoptotic antitumor drug in chemosensitive and chemoresistant bladder cancer $(30,31)$.

The sensitivity of urothelial cancer cell lines to TRAIL-induced cell death varies among different cell lines (32). In the present study, the sensitivity of urothelial cancer cell lines to TRAIL-induced cell death was similar to that reported previously (33).

Li et al analyzed the correlation between the expression of the TRAIL receptors TRAILR1 (DR4) and TRAILR2 (DR5) and its effects on prognosis. They reported an expression rate of TRAILR1 in $75.1 \%$ and of TRAILR 2 in $74.2 \%$ of the bladder cancer specimens (24). The expression of TRAIL receptors was shown to be a resistance factor in different tumor entities (21-23). In the present study, an elevated expression of TRAILR1 was observed in chemotherapy-resistant and TRAIL cross-resistant RT112 ${ }^{\mathrm{r}} \mathrm{GEMCI}^{20}$ and RT112 ${ }^{\mathrm{r}} \mathrm{CDDP}^{1000}$ sublines compared with chemotherapy-naïve RT112 cells. However, receptor expression does not appear to be the only resistance factor. Furthermore, IAP expression was similarly 


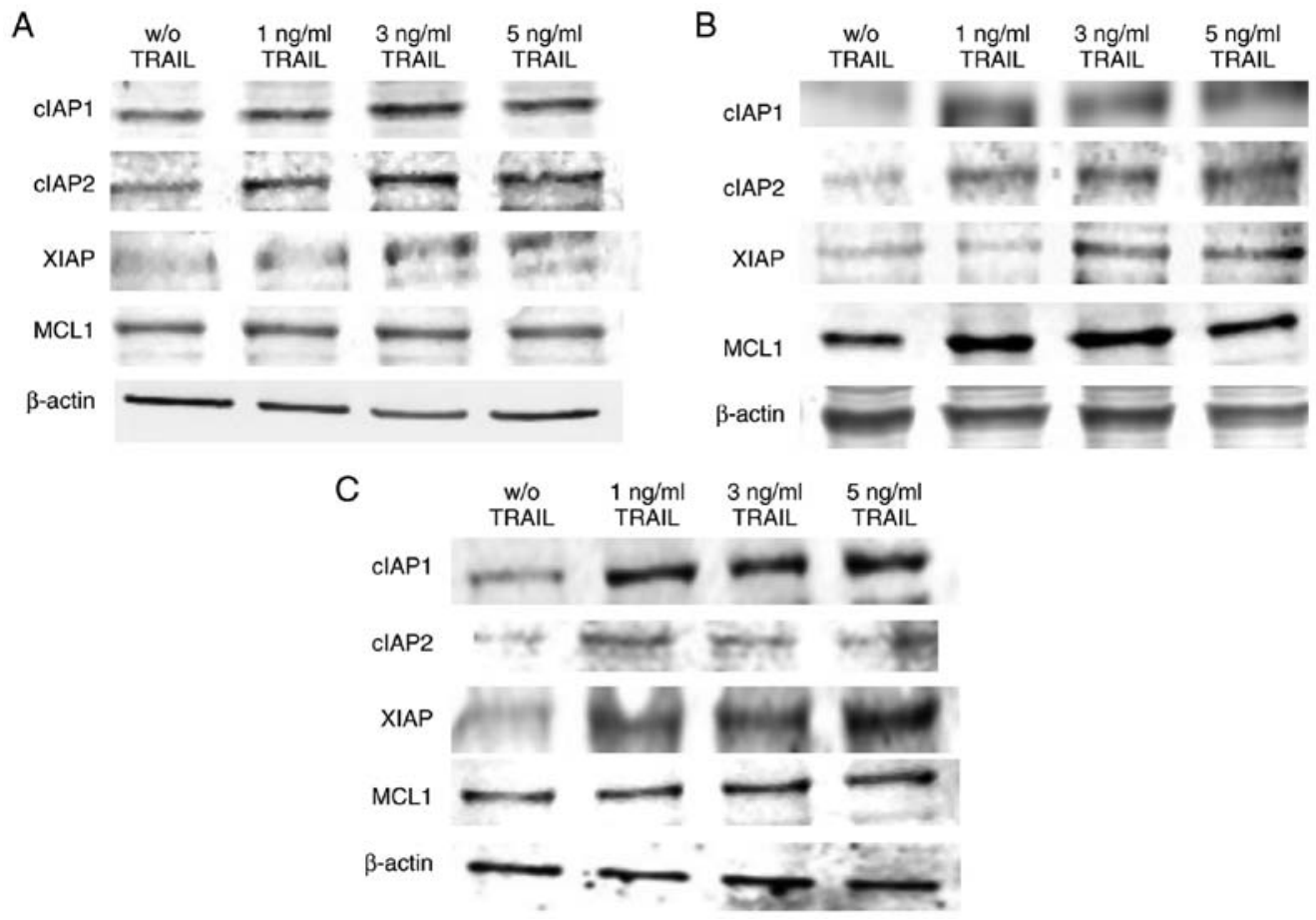

Figure 2. Protein expression following treatment with TRAIL. Western blotting following incubation for $24 \mathrm{~h}$ with increasing concentrations of TRAIL in (A) RT112, (B) RT112 GEMCI $^{20}$ and (C) RT112 ${ }^{\mathrm{r}} \mathrm{CDDP}^{1000}$ cells. The results shown are representative of three independent experiments. TRAIL, tumor necrosis factor-related apoptosis-inducing ligand; cIAP, cellular inhibitor of apoptosis protein; XIAP, x-linked inhibitor of apoptosis protein; Mcl-1, myeloid leukemia cell differentiation protein 1; RT112 ${ }^{\mathrm{r}} \mathrm{GEMCI}^{20}$, gemcitabine-resistant RT112 subline; RT112 ${ }^{\mathrm{r}} \mathrm{CDDP}^{1000}$, cisplatin-resistant RT112 subline.

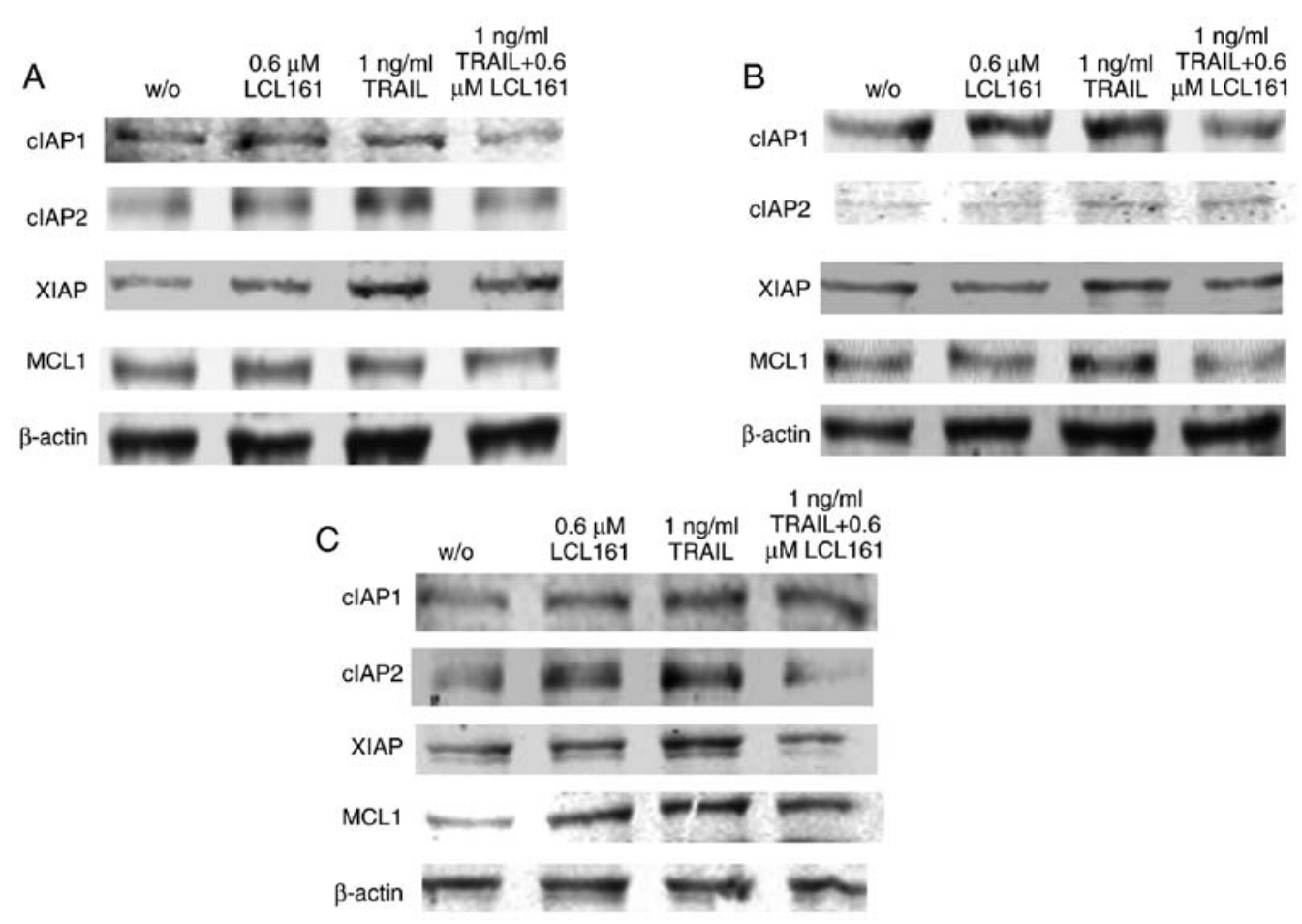

Figure 3. Protein expression following combination therapy with TRAIL and LCL-161. Western blotting following incubation for $24 \mathrm{~h}$ with LCL-161, TRAIL,

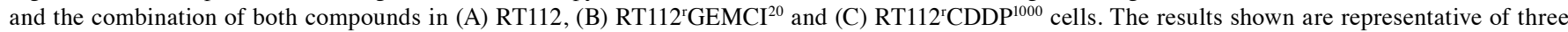
independent experiments. TRAIL, tumor necrosis factor-related apoptosis-inducing ligand; cIAP, cellular inhibitor of apoptosis protein; XIAP, $\mathrm{x}$-linked inhibitor of apoptosis protein; Mcl-1, myeloid leukemia cell differentiation protein 1; RT112 ${ }^{\mathrm{r}} \mathrm{GEMCI}^{20}$, gemcitabine-resistant RT112 subline; RT112 ${ }^{\mathrm{r}} \mathrm{CDDP}^{1000}$, cisplatin-resistant RT112 subline.

enhanced in both RT112 sublines with acquired chemotherapy resistance and TRAIL cross-resistance $\left(\mathrm{RT} 112^{\mathrm{r}} \mathrm{GEMCI}^{20}\right.$ and
RT112 $\left.{ }^{\mathrm{r}} \mathrm{CDDP}^{1000}\right)$ compared with parental chemotherapy-naïve and TRAIL-sensitive RT112 cells. Overexpression of IAPs, 

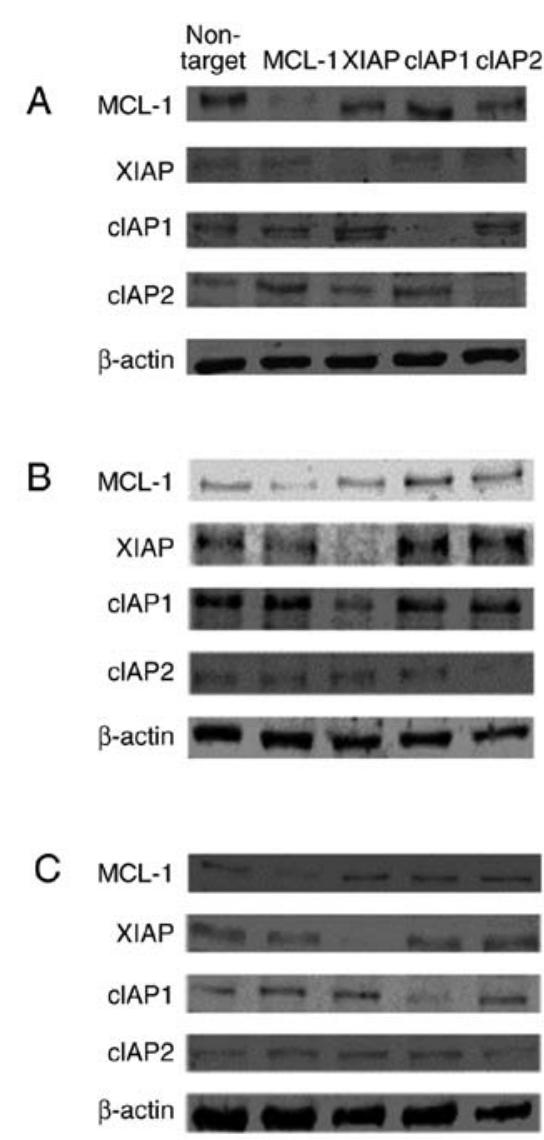
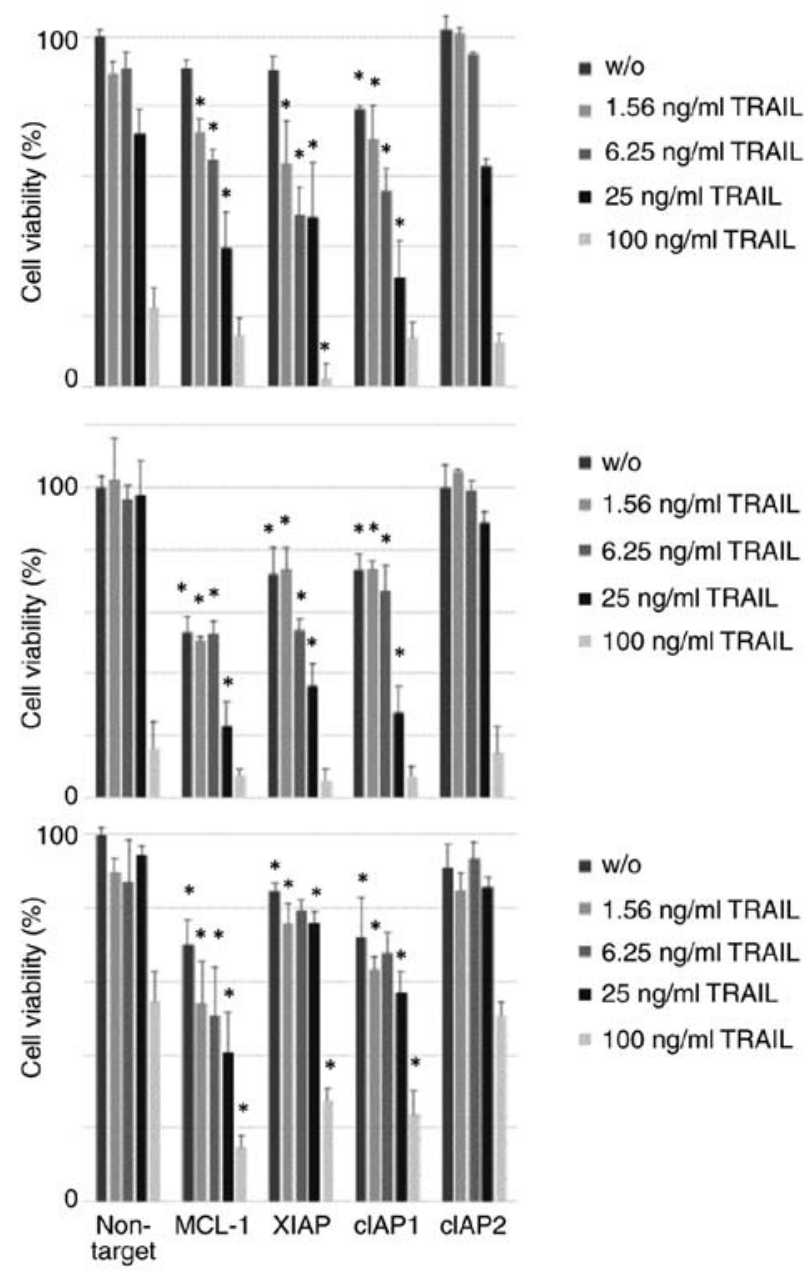

Figure 4. Effects of selective depletion of IAPs and Mcl-1 on cancer cell viability. Effects of siRNA-mediated depletion of cIAP1, cIAP2, XIAP and Mcl-1 on TRAIL sensitivity in (A) RT112, (B) RT112 ${ }^{\mathrm{r}} \mathrm{GEMCI}^{20}$ and (C) RT112 ${ }^{\mathrm{r}} \mathrm{CDDP}^{1000}$ cells following incubation for $48 \mathrm{~h}$. Western blots (left) showing depletion of the knockdown protein. Cell viability was measured via the MTT assay (right), demonstrating the effect of siRNA depletion of the proteins cIAP1, cIAP2, XIAP and Mcl-1 on sensitivity to TRAIL treatment. The results shown are representative of three independent experiments. ${ }^{*}<0.05$ relative to control. TRAIL, tumor necrosis factor-related apoptosis-inducing ligand; IAPs, inhibitors of apoptosis; cIAP, cellular inhibitor of apoptosis protein; XIAP, X-linked inhibitor of apoptosis protein; Mcl-1, myeloid leukemia cell differentiation protein 1; RT112 ${ }^{\mathrm{r}} \mathrm{GEMCI}^{20}$, gemcitabine-resistant RT112 subline; RT112 ${ }^{\mathrm{r}} \mathrm{CDDP}^{1000}$, cisplatin-resistant RT112 subline.

such as XIAP, and pro-survival Bcl-2 members, such as Mcl-1, have be shown to be an important cause of TRAIL resistance in bladder cancer and other cancer entities (32,34-37). IAP expression has also been shown to predict prognosis in human urothelial carcinoma patients in an intrinsic resistance setting (38). In the present study, a dose-dependent upregulation of the IAPs cIAP1, cIAP2 and XIAP was detected as a possible response of cancer cells to the pro-apoptotic TRAIL stimulus (Fig. 2).

Different research groups demonstrated that SMAC mimetics exerted anticancer effects and enhanced the efficacy of TRAIL and cytotoxic anticancer drugs in chemosensitive or intrinsically drug-resistant urothelial cancer cells (32,39-41). Combinations of LCL-161 and cytotoxic chemotherapies are currently being developed (41). In the present study, the SMAC mimetic LCL-161 that targets IAPs, including cIAP1, cIAP2 and XIAP, affected the viability of chemosensitive and chemoresistant urothelial cancer cells at low micromolar concentrations (Table I). In a study of the Pediatric Preclinical Testing Program, only 3 of 23 pediatric cancer cell lines demonstrated effects in a similar concentration range (42). Moreover, the urothelial cancer cell lines from our panel exhibited a higher LCL-161 sensitivity compared with hepatocellular carcinoma cells in a recently published report (16).

Since IAP and Mcl-1 expression was enhanced in cell lines with acquired chemotherapy resistance and TRAIL cross-resistance in the present study, we further sought to evaluate whether the combination of TRAIL with the SMAC mimetic LCL-161 could improve the efficacy of TRAIL treatment. Following treatment with a sublethal dose of LCL-161, no changes in the expression of IAPs or Mcl-1 were detected (Fig. 3). Of note, the combination of low-dose LCL-161 with TRAIL was able to reverse the aforementioned upregulation of pro-survival molecules, such as cIAP1, cIAP2 and XIAP (Fig. 3). Moreover, TRAIL sensitivity was markedly increased in chemotherapy-naïve as well as in chemoresistant cancer cell lines when combined with LCL-161 (Table I). Therefore, the data of the present study suggest that TRAIL, particularly in combination with the SMAC mimetic LCL-161, may be a treatment option for urothelial cancer cells, including those with acquired resistance to standard gemcitabine and cisplatin combination chemotherapy after failure of first-line chemotherapy. 
Finally, we aimed to evaluate the effects of RNAi-mediated depletion of cIAP1, cIAP2, XIAP and Mcl-1 on TRAIL sensitivity. The resensitization of tumor cells to TRAIL was confirmed by depletion of antiapoptotic proteins with siRNA. Following specific depletion of the antiapoptotic proteins and treatment with TRAIL, a dose-dependent effect on cell survival was observed for cIAP1, XIAP and Mcl-1. Depletion of cIAP2 was not associated with survival (Fig. 4).

To the best of our knowledge, the present study is the first to examine the role of TRAIL as a drug against urothelial cancer cells with acquired resistance to standard chemotherapy with gemcitabine and cisplatin. It was demonstrated that TRAIL and, in case of acquired chemotherapy resistance, TRAIL in combination with the SMAC mimetic LCL-161, may represent a promising treatment option for urothelial cancer. Therefore, further clinical evaluation is warranted.

\section{Acknowledgements}

The authors would like to thank Sebastian Grothe for technical support.

\section{Funding}

The present study was supported by the charity Hilfe für krebskranke Kinder Frankfurt e.V., its trust Frankfurter Stiftung für krebskranke Kinder, the Patenschaftsmodell of the Clinics of the Goethe-University, the Kent Cancer Trust, and the Royal Society (RG120199).

\section{Availability of data and materials}

The original datasets of the present study are available from the corresponding author on reasonable request.

\section{Authors' contributions}

SV substantially contributed to the conception and design, acquisition of data and analysis, drafting of the manuscript and revising it critically for important intellectual content and final approval of the version to be published. HS substantially contributed to the conception and design, acquisition of data and analysis. MB acquired data and analysis. MM drafted the manuscript and revised it critically for important intellectual content. RW drafted the manuscript and revised it critically for important intellectual content. FR drafted the manuscript and revised it critically for important intellectual content. JC substantially contributed to the conception and design, drafting of the manuscript and revising it critically for important intellectual content and finall approval of the version to be published. All authors have read and approved the final manuscript.

\section{Ethics approval and consent to participate}

Not applicable.

\section{Patient consent for publication}

Not applicable.

\section{Competing interests}

All the authors declare that they have no competing interests.

\section{References}

1. von der Maase H, Sengelov L, Roberts JT, Ricci S, Dogliotti L, Oliver T, Moore MJ, Zimmermann A and Arning M: Long-term survival results of a randomized trial comparing gemcitabine plus cisplatin, with methotrexate, vinblastine, doxorubicin, plus cisplatin in patients with bladder cancer. J Clin Oncol 23: 4602-4608, 2005.

2. Pectasides D, Pectasides M and Economopoulos T: Systemic chemotherapy in locally advanced and/or metastatic bladder cancer. Cancer Treat Rev 32: 456-470, 2006.

3. Bellmunt J, Théodore C, Demkov T, Komyakov B, Sengelov L, Daugaard G, Caty A, Carles J, Jagiello-Gruszfeld A, Karyakin O, et al: Phase III trial of vinflunine plus best supportive care compared with best supportive care alone after a platinum-containing regimen in patients with advanced transitional cell carcinoma of the urothelial tract. J Clin Oncol 27: 4454-4461, 2009.

4. Bellmunt J, Powles T and Vogelzang NJ: A review on the evolution of PD-1/PD-L1 immunotherapy for bladder cancer: The future is now. Cancer Treat Rev 54: 58-67, 2017.

5. Carswell EA, Old LJ, Kassel RL, Green S, Fiore N and Williamson B: An endotoxin-induced serum factor that causes necrosis of tumors. Proc Natl Acad Sci USA 72: 3666-3670, 1975.

6. Tracey KJ, Lowry SF and Cerami A: Cachetin/TNF-alpha in septic shock and septic adult respiratory distress syndrome. Am Rev Respir Dis 138: 1377-1379, 1988.

7. Kruyt FA: TRAIL and cancer therapy. Cancer Lett 263: 14-25, 2008.

8. Walczak H, Miller RE, Ariail K, Gliniak B, Griffith TS, Kubin M, Chin W, Jones J, Woodward A, Le T, et al: Tumoricidal activity of tumor necrosis factor-related apoptosis-inducing ligand in vivo. Nat Med 5: 157-163, 1999.

9. Ashkenazi A, Pai RC, Fong S, Leung S, Lawrence DA, Marsters SA, Blackie C, Chang L, McMurtrey AE, Hebert A, et al: Safety and antitumor activity of recombinant soluble Apo2 ligand. J Clin Invest 104: 155-162, 1999.

10. Dimberg LY, Anderson CK, Camidge R, Behbakht K, Thorburn A and Ford HL: On the TRAIL to successful cancer therapy? Predicting and counteracting resistance against TRAIL-based therapeutics. Oncogene 32: 1341-1350, 2013.

11. von Karstedt S, Montinaro A and Walczak H: Exploring the TRAILs less travelled: TRAIL in cancer biology and therapy. Nat Rev Cancer 17: 352-366, 2017.

12. Steele LP, Georgopoulos NT, Southgate J, Selby PJ and Trejdosiewicz LK: Differential susceptibility to TRAIL of normal versus malignant human urothelial cells. Cell Death Differ 13: 1564-1576, 2006.

13. Makin G and Hickman JA: Apoptosis and cancer chemotherapy. Cell Tissue Res 301: 143-152, 2000.

14. Tan ML, Ooi JP, Ismail N, Moad AI and Muhammad TS: Programmed cell death pathways and current antitumor targets. Pharm Res 26: 1547-1560, 2009.

15. Protzel $\mathrm{C}$ and Hakenberg OW: Emerging apoptosis agonists for bladder cancer. Expert Opin Emerg Drugs 14: 607-618, 2009.

16. Chen KF, Lin JP, Shiau CW, Tai WT, Liu CY, Yu HC, Chen PJ and Cheng AL: Inhibition of Bcl-2 improves effect of LCL161, a SMAC mimetic, in hepatocellular carcinoma cells. Biochem Pharmacol 84: 268-277, 2012.

17. Fulda $\mathrm{S}$ and Vucic D: Targeting IAP proteins for therapeutic intervention in cancer. Nat Rev Drug Discov 11: 109-124, 2012.

18. Infante JR, Dees EC, Olszanski AJ, Dhuria SV, Sen S, Cameron S and Cohen RB: Phase I dose-escalation study of LCL161, an oral inhibitor of apoptosis proteins inhibitor, in patients with advanced solid tumors. J Clin Oncol 32: 3103-3110, 2014.

19. Fulda S: Molecular pathways: Targeting inhibitor of apoptosis proteins in cancer-from molecular mechanism to therapeutic application. Clin Cancer Res 20: 289-295, 2014.

20. Michaelis M, Rothweiler F, Barth S, Cinatl J, van Rikxoort M, Löschmann N, Voges Y, Breitling R, von Deimling A, Rödel F, et al: Adaptation of cancer cells from different entities to the MDM2 inhibitor nutlin-3 results in the emergence of p53-mutated multi-drug resistant cancer cells. Cell Death Dis 2: e243, 2011. 
21. Riccioni R, Pasquini L, Mariani G, Saulle E, Rossini A, Diverio D, Pelosi E, Vitale A, Chierichini A, Cedrone M, et al: TRAIL decoy receptors mediate resistance of acute myeloid leukemia cells to TRAIL. Haematologica 90: 612-624, 2005.

22. Morizot A, Mérino D, Lalaoui N, Jacquemin G, Granci V, Iessi E, Lanneau D, Bouyer F, Solary E, Chauffert B, et al: Chemotherapy overcomes TRAIL-R4-mediated TRAIL resistance at the DISC level. Cell Death Differ 18: 700-711, 2011.

23. Wang W, Zhang M, Sun W, Yang S, Su Y, Zhang H, Liu C, Li X, Lin L, Kim S, et al: Reduction of Decoy receptor 3 enhances TRAIL-mediated apoptosis in pancreatic cancer. PLoS One 8: e74272, 2013.

24. Li Y, Jin X, Li J, Jin X, Yu J, Sun X, Chu Y, Xu C, Li X, Wang X, et al: Expression of TRAIL, DR4, and DR5 in bladder cancer: Correlation with response to adjuvant therapy and implications of prognosis. Urology 79: 968.e7-e15, 2012.

25. Suzman DL, Agrawal S, Ning YM, Maher VE, Fernandes LL, Karuri S, Tang S, Sridhara R, Schroeder J, Goldberg KB, et al: FDA approval summary: Atezolizumab or pembrolizumab for the treatment of patients with advanced urothelial carcinoma ineligible for cisplatin-containing chemotherapy. Oncologist 24: 563-569, 2019.

26. O'Kane HF, Watson CJ, Johnston SR, Petak I, Watson RW and Williamson KE: Targeting death receptors in bladder, prostate and renal cancer. J Urol 175: 432-438, 2006.

27. Sharma SV, Haber DA and Settleman J: Cell line-based platforms to evaluate the therapeutic efficacy of candidate anticancer agents. Nat Rev Cancer 10: 241-253, 2010.

28. Domingo-Domenech J, Vidal SJ, Rodriguez-Bravo V, Castillo-Martin M, Quinn SA, Rodriguez-Barrueco R, Bonal DM, Charytonowicz E, Gladoun N, de la Iglesia-Vicente J, et al: Suppression of acquired docetaxel resistance in prostate cancer through depletion of notch- and hedgehog-dependent tumor-initiating cells. Cancer Cell 22: 373-388, 2012.

29. Murtaza M,Dawson SJ, Tsui DW, Gale D, Forshew T, Piskorz AM, Parkinson C, Chin SF, Kingsbury Z, Wong AS, et al: Non-invasive analysis of acquired resistance to cancer therapy by sequencing of plasma DNA. Nature 497: 108-112, 2013.

30. Vallo S, Michaelis M, Rothweiler F, Bartsch G, Gust KM, Limbart DM, Rödel F, Wezel F, Haferkamp A and Cinatl J Jr: Drug-resistant urothelial cancer cell lines display diverse sensitivity profiles to potential second-line therapeutics. Transl Oncol 8: 210-216, 2015 .

31. Mani J, Vallo S, Rakel S, Antonietti P, Gessler F, Blaheta R, Bartsch G, Michaelis M, Cinatl J, Haferkamp A and Kögel D Chemoresistance is associated with increased cytoprotective autophagy and diminished apoptosis in bladder cancer cells treated with the BH3 mimetic (-)-Gossypol (AT-101). BMC Cancer 15: 224, 2015.
32. Metwalli AR, Khanbolooki S, Jinesh G, Sundi D, Shah JB, Shrader M, Choi W, Lashinger LM, Chunduru S, McConkey DJ, et al: Smac mimetic reverses resistance to TRAIL and chemotherapy in human urothelial cancer cells. Cancer Biol Ther 10: 885-892, 2010

33. Szliszka E, Mazur B, Zydowicz G, Czuba ZP and Król W: TRAIL-induced apoptosis and expression of death receptor TRAIL-R1 and TRAIL-R2 in bladder cancer cells. Folia Histochem Cytobiol 47: 579-585, 2009.

34. Jinesh GG, Chunduru S and Kamat AM: Smac mimetic enables the anticancer action of BCG-stimulated neutrophils through TNF- $\alpha$ but not through TRAIL and FasL. J Leukoc Biol 92: 233-244, 2012.

35. Foster FM, Owens TW, Tanianis-Hughes J, Clarke RB, Brennan K, Bundred NJ and Streuli $\mathrm{CH}$ : Targeting inhibitor of apoptosis proteins in combination with ErbB antagonists in breast cancer. Breast Cancer Res 11: R41, 2009.

36. Fulda S, Meyer E and Debatin KM: Inhibition of TRAIL-induced apoptosis by Bcl-2 overexpression. Oncogene 21: 2283-2294, 2002.

37. Han J, Goldstein LA, Gastman BR and Rabinowich H: Interrelated roles for Mcl-1 and BIM in regulation of TRAIL-mediated mitochondrial apoptosis. J Biol Chem 281: 10153-10163, 2006.

38. Chen X, Wang T, Yang D, Wang J, Li X, He Z, Chen F, Che X and Song X: Expression of the IAP protein family acts cooperatively to predict prognosis in human bladder cancer patients. Oncol Lett 5: 1278-1284, 2013.

39. Wang J, Zeng F, Wang L, Zhu Z and Jiang G: Synthetic Smac peptide enhances chemo-sensitivity of bladder cancer cells. J Huazhong Univ Sci Technolog Med Sci 28: 304-307, 2008.

40. Yang D, Song X, Zhang J, Ye L, Wang S, Che X, Wang J, Zhang Z, Wang $L$ and Shi W: Therapeutic potential of siRNA-mediated combined knockdown of the IAP genes (Livin, XIAP, and Survivin) on human bladder cancer T24 cells. Acta Biochim Biophys Sin (Shanghai) 42: 137-144, 2010.

41. Griffith TS, Kucaba TA, O'Donnell MA, Burns J, Benetatos C, McKinlay MA, Condon S and Chunduru S: Sensitization of human bladder tumor cells to TNF-related apoptosis-inducing ligand (TRAIL)-induced apoptosis with a small molecule IAP antagonist. Apoptosis 16: 13-26, 2011.

42. Houghton PJ, Kang MH, Reynolds CP, Morton CL, Kolb EA, Gorlick R, Keir ST, Carol H, Lock R, Maris JM, et al: Initial testing (stage 1) of LCL161, a SMAC mimetic, by the pediatric preclinical testing program. Pediatr Blood Cancer 58: 636-639, 2012. 